LAN Hailin

\title{
Corporate strategic management: Static and dynamic paradigms
}

\author{
(C) Higher Education Press and Springer-Verlag 2009
}

\begin{abstract}
Based on an analysis of the dynamic trend of the environment in which Chinese enterprises operate and the theory of dynamic competition, this paper seeks to propose a new strategic management pattern-the "dynamic paradigm", which has mainly resulted from an integration of the theoretic contributions of the two strategic management streams. It ultimately aims at enhancing the effectiveness and efficiency of strategic management in an environment full of uncertainties. The dynamic paradigm designed to explore today's real business world is characterized by: 1) viewing strategic management as a process of both proactive plans and in-the-process reaction, both point and process decision-making and both rational and non-rational decision-making; 2) stressing the roles played by speed and innovation in the dynamic competition; 3 ) highlighting the inherent ties and the interaction among the three phases of strategic management; 4) emphasizing the critical impacts on the effectiveness and efficiency of strategic management by corporate governance, organizational structure, managerial mechanism, mode of control, composition of top-management team and corporate culture.
\end{abstract}

Keywords dynamic competition, corporate strategies, strategic management pattern

摘要 根据对中国企业环境动态化与动态竞争的分析, 以整合两大战略管理流派的 理论贡献为切入点, 以提高动态环境下企业战略管理的有效性和效率为目的, 提出 一个新的战略管理模式— “动态模式”。这个新的模式把战略管理行为看成是事 前计划与事中反应的结合, “点决策” 与 “过程决策” 的结合, 理性决策与非理性

Translated and revised from Nankai guanli pinglun 南开管理评论 (Nankai Business Review), 2007,10(5): 31-35

LAN Hailin $(\bowtie)$

Business School of Administration, South China University of Technology, Guangzhou 510640, China

E-mail: bmhllan@scut.edu.cn 
决策的结合; 强调速度与创新在动态竞争中的作用; 关注战略管理三个阶段之间的 内在联系与交叉影响; 重视公司治理、组织结构、管理机制、控制方式、高层管理 团队构成以及企业文化对战略管理有效性与效率的保证作用。

关键词 动态竞争, 企业战略, 战略管理模式

\section{Introduction}

The introduction and promotion of business strategic management theory gained momentum between the mid-1980s and the mid-1990s. At that time, China's business environment was characterized by abundant opportunities and less intense competitions. The introduction of corporate strategic management theory and methods was mainly from western countries (Abrahamson and Fombrun, 1994). This paper names such kind of strategic management pattern "static paradigm" since it is based on rationalism school and applies to relatively static environment.

However, the static paradigm now faces an increasingly awkward situation in China's current practice of strategic management: 1) In implementing corporate strategies, proactive plan decreases, while process reaction or innovative acts increase. Excellent strategic plans are often not planed in advance, but emerge as a result of summing-up of prior experience; 2) More strategic decisions are made at the stage of strategy implementation rather than formulation; 3) In an increasingly dynamic environment, time urgency and limited information highlight the impacts of irrational factors on corporate strategic decision. Accordingly, the scientific nature and applicability of strategic management theory are seriously challenged. Meanwhile, Chinese businesses' strategic management practices have advanced far ahead of extant strategic management theories. Thus the most urgent task for us now is to find a new corporate strategic management pattern.

\section{The rationalism school and the "static paradigm" of strategic management}

Corporate strategic management came into being as a result of the substitute of rationalism school for empiricism. After the 1930s, management scholars began to distinguish and discuss the differences between operation and decision-making, between conventional decision-making and non-conventional decision-making, and between strategic decision-making and management decision, aiming to encourage managers to spend more time and adopt more scientific methods in 
making strategic decisions (Andrews, 1981). In the late 1950s, scholars of corporate strategic management endeavored to construct conceptual models, process models as well and invent scientific analysis methods for strategy formation. Later, these scholars were called the genre of rationalism school, including the design school, the planning school and the positioning school (Ansoff, 1965).

The design school holds that "strategy formation should be a conscious and thoughtful thinking process" (Chandler, 1962). Thus strategy development needs relevant model "to facilitate the finding of the match between external environment and internal capacity" (Christensen et al., 1982). It represents the most influential views on strategy formulation process. Their main contributions include the process model for strategic development, the SWOT model for strategic choice and the criteria of potential strategy evaluation, such as consistency, coordination, advantage and feasibility, etc.

Consistent with and based on the key theoretical viewpoints of the design school, the planning school divides strategic management process into three stages of formulation, implementation, namely evaluation and control, converting the original simple and informal strategy formation model into a very sophisticated process model consisting of a series of steps such as goal set, external environment review, internal environment review and strategy evaluation. In an explicit and rigorous way, the planning school further decomposes the strategy contents system into target system, budget system, strategic system and procedures system (D'Aveni, 1994). The planning school argues that "strategy emerges in a controlled, conscious formal planning process, which was broken down into clear steps... and by the support of analysis technologies". And the strategy developed and adopted by a formal process should be implemented through target decomposition, budgets, procedures and intermediate plans (George, 1996).

Contrary to the above two schools focusing on the process and methods in strategic decision-making process, the positioning school places its focus on the strategy contents. Believing that there is only a very small yet commonly used variety of key strategies for enterprises to choose from, scholars in the positioning school have attempted to find out a group of strategies that can be generally applied to all enterprises (Hayes and Jaikumar, 1988). Although the school agrees that strategy development should be a controlled, conscious process, it argues that the choosing of a suitable strategy positioning needs more rational methods and scientific calculations.

Since the genre of rationalism school came into being in the context of a relatively stable business environment, relatively abundant market opportunities and less intensive competitions among enterprises in the same industry, the criticism it later received mainly centered around the following three basic 
premises: 1) Business environment is relatively stable and predictable, corporate strategy thus can be scheduled in advance; 2) Top managers in the process of developing strategies have sufficient time and all the information needed; 3) One's brain is able to deal with all the information needed for strategic decisions making. Therefore, CEOs can be fully responsible for the strategy formulation. Nevertheless, the emergence of the above three streams of thought still has its special historical contributions to the development of corporate strategic management. It is under the influence of these three schools that a widely accepted and adopted strategic management pattern was developed. In order to reflect the characteristics of the strategic management pattern adapted to such a static environment in a better way, we call the paradigm the "static paradigm" in the rest of this paper. As shown in Fig. 1, the main features of the "static paradigm" include:

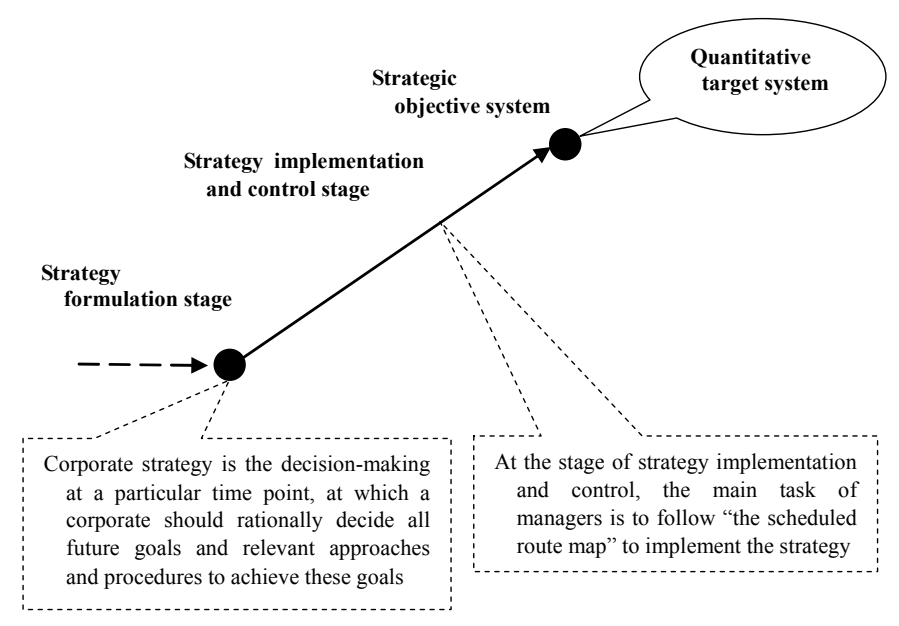

Fig. 1 Sketch map of the "static paradigm" and "point decision-making" in corporate strategic management

First, corporate strategic decision-making is a "decision-making at some specific time points". Before the start of strategy adjustment or a new business cycle, enterprises strategic managers determined to execute strategic management, study those issues which have important, long-term and overall impacts on their enterprises' future development and make relevant strategies as accurate, comprehensive and detailed as possible. This is the core tasks of corporate strategic management at the stage of strategy formulation (Jelinek and Amar, 1983). Once the corporate strategies are decided, what top managers need to do in the next three years or five years at the stage of strategy implementation is to execute these strategies, which is the so-called "the separation of strategy formulation and implementation". 
Second, the strategic behaviors of an enterprise shall be predetermined and follow a certain "route map". If one agrees that corporate strategic decision-making is made at a certain "time point", one would naturally agree that all strategic behaviors of an enterprise should be planed in advance, and exclude those emergency response. According to the rationalism school, decisions made at the strategy formulation stage include not only the goals, objectives, strategies and policies, but also the secondary plans, plans of action, major operation procedures, and relevant budgets (Jiang and Lan, 2004). Thus the development of such a strategy basically regulates almost every strategic behavior in future implementation of the strategy, hence the name of "the theory of predetermination of strategic plans".

Third, goal-setting is the core of strategic decision-making. According to rationalism school, the core of corporate strategic decision-making is to set corporate goals. Some rationalists go even further in claiming that strategy making is goal setting (Lan, 2004). In order to improve the effectiveness and efficiency of corporate strategy implementation, these scholars put much emphasis on the comprehensiveness, quantification and measurableness of enterprise goals. Thus enterprises at the stage of strategy formulation prefer the following strategic behaviors: 1) Set goals for all the important business activities; 2) Emphasize the quantification of all goals; 3) Further decompose quantitative goals into smaller and specified sub-goals. The rationalism school thinks that the more specific and quantitative an enterprise's strategic goals, the easier the following strategic evaluation and control.

Fourth, a firm's strategy choice is a result of rational decision-making. Aiming at solving the limitations of the empiricism, the rationalism school puts forward the correctness of the corporate strategic choice relies on the level of rational thinking and scientificalness of the decision-making method adopted by strategy makers. Among different schools in the rationalism school, the design school emphasizes the importance of strategic thinking mode; the planning school mainly stresses the scientificalness of the process and methods of strategy formulation; and the positioning school focuses on the scientificalness nature of the strategic choice. Thanks to the contributions of these schools, the process model and level model of the strategic management were established. Following the requirements and steps of these models and approaches, the scientificalness of strategic decision-making can be guaranteed, hence the name "the standardization of strategy formation process" (Lan, 2001).

Fifth, the key of corporate strategy implementation and control is to complete projects in conformity with the required quality, quantity and time. Since enterprise strategy is a "point decision" and the main strategic behaviors are well planned in advance, when an enterprise enters the strategy implementation stage, its main task shall be the implementation of these predetermined strategic plans 
effectively and efficiently to achieve strategic objectives. Although enterprises at the stage of strategy implementation still needs to make timely evaluations and adjustments to their strategies, the rationalism school argues that 1) No matter whether adjustment is because of environmental change or ineffective implementation, the problem lies in the strategy itself since a good strategy never needs any adjustments; 2) Both active or passive adjustments made to strategies during the course of strategy implementation should be conducted in line with predetermined plans. As a result, it is necessary to make plans for emergencies in advance or start a new round of strategic management process (Lorange, 1980).

From the mid-1980s to the mid-1990s, China was still at the beginning of her long economy transition. The main task of that period was to reform thoroughly the planned economy system and fulfill the separation of government functions from enterprise management by applying the factory director responsibility system and contract and responsibility system. In so doing, the Chinese government hopes that hundreds and thousands of state-owned enterprises can become active market participants characterized by self-management, self-development, self-accumulation and self-discipline, and arouse the enthusiasm of these enterprises to promote the development of social productivity to meet Chinese people's ever-growing demands for more material goods.

Under such a macro-economy background, China adopted theories and techniques of western corporate strategic management to facilitate managers in state-owned enterprises to change their mindsets in the following ways: 1) Pay more attention to the differences between internal conventional and non-conventional decision-making means to efficiently allocate their energy; 2) Pay more attention to the distinction between strategic and managerial decision-making and learn to be more market/competition oriented; 3) Learn scientific methods of strategic decision-making to reduce blindness and empiricism in making major decisions; 4) Pay more attention to the scientific nature of the strategic objectives and implementation of objectives management and comprehensively enhance the effectiveness and efficiency of corporate management. Based on the principles of gradualism and applicability, almost all scholars engaging in the introduction and promotion of corporate strategic management theories choose to introduce the leading theory in western strategic management field - the genre of rationalism school and the "static paradigm" of corporate strategic management.

\section{Criticism from irrationalism school and limitations of the "static paradigm"}

Before China's introduction of rationalism school and promotion and application 
of the "static paradigm", western strategic management practices and theories had undergone tremendous changes. Seven news schools characterized by irrationalism school emerged, namely the entrepreneur school, the cognitive school, the learning school, the authority school, the culture school, the environment school, and the structure school. The non-related diversification movement flourished in the late 1960s finally came to an end in the late 1970s and early 1980s and western companies paid heavy prices for their attempts in non-related diversification. Accordingly, related practices and theories of corporate strategic management faced greatest crisis of both strategic management theory and public confidence.

Based on careful synthesis of corporate strategic behaviors of the period, three important facts were identified: 1) The business environment was becoming relatively more dynamic in comparison with the former static environment; 2) Corporate decision-markers had to make do with limited time and information when making decisions, thus strategic decision can only be a suboptimal choice; 3) Corporate strategic decisions should be collectively made by a managerial team rather than an individual decision. These important findings led directly to a new trend of thought in the field of corporate strategic management- the so-called irrationalism school, which argues that the traditional rationalism school, particularly the planning school have three major fallacies, namely the predetermined plan, the standardized plan implementation procedures, and the separation between goal setting and implementation.

Scholars during this period conducted empirical studies on the real decision-making behaviors by adopting theories and approaches from a wide variety of disciplines such as politics, sociology, psychology, anthropology etc. Based on the results of these studies, scholars questioned the rationalism views and its correspondent "static paradigm" from the following perspectives:

First, corporate strategic behaviors include unplanned responses to unexpected changes. By tracking the development histories of a number of enterprises, scholars found that practical corporate strategy behaviors are composed of proactive strategic behaviors and responsive strategic behaviors. Therefore, they argued that there are two corresponding corporate strategies, namely the planned strategy and the realized strategy (Mintzberg, 1994).

Second, strategic decision-makers need to make new strategic decisions during the course of strategy implementation to cope with new and unexpected situations. As business environment becomes more and more dynamic, increased interaction among different enterprises has laid an unprecedented emphasis on the importance of speed, learning and innovation. Therefore, the top echelon of an enterprise shall adjust their strategies from time to time in accordance with changes in the environment and competitors. Though some of these newly made decisions seem to be responsive in nature, they are of great strategic significance 
for an enterprise in establishing and maintaining long-term competitiveness if these responsive behaviors are either innovative or can exert lasting restraints on one's competitors (Mintzberg, Ahlstrand and Lampel, 1998).

Third, the core of corporate strategy has become increasingly difficult to concretize and quantify. Under the circumstance of a growingly volatile environment, it is virtually impossible for enterprises to set up long-term, concrete and quantified goals in advance. As interaction and competition become more important, the quality of a strategy does not depend solely on how carefully it was made or the consistency of inner systems within an enterprise, but on, to a large extent, the counter measures one's competitors will take. Accordingly, the importance of making a quantified goal system decreases for too much attention paid to quantified goals may lead to the neglect of the enterprise's development direction and strategic positioning in the process of strategy implementation in the long run. In addition, if strategy regulation were too specific, response speed and innovation capacities of the enterprise in implementing these strategies may be lowered (Mintzberg, 1987). Consequently, the irrationalism school points out that the maintenance of strategic intent, tenet and positioning is more important than the realization of quantitative goals and operable plans as well. And the achievement of qualitative goals is more important than that of the quantitative goals.

Fourth, irrational factors may play more important roles in strategic decision-making. Scholars of irrationalism school think that, during the process of strategy implementation, corporate strategy makers must make new decisions, take into account the competitors' reactions and pay attention to speed and innovation. Thus completely rational decision-making approaches will affect negatively rather than enhance speed and innovation. Similarly, major strategic actions of a vast majority of enterprises are the outcomes of collective decision-making of senior managers. The very irrational factors influencing collective decision-making will also affect corporate strategic decision-making. It is also pointed out that the values of corporate top managers and irrational factors in decision-making exert increasingly important impact on corporate strategy decision-making.

Fifth, the impact of speed and innovation on strategy implementation and control process should be taken into consideration (Steiner, 1969). As the environmental predictability declines, the importance of interaction and competition increases, innovation and speed have increasingly become the main sources of profit and advantages. The core tasks at the stage of strategy implementation and control have undergone fundamental changes. Though a strict and accurate implementation of pre-planned strategy still remains important, especially for maintaining an enterprise's strategic intent, tenet and positioning, adaption to the environment and competitors' strategic changes, timely and 
proactive achievement of enterprise goals, corresponding approaches, adjustment of enterprise strategies, and innovation have become more important.

Sixth, the division of corporate strategic management into three stages may not be very scientific for it is very difficult to distinguish these successive stages of corporate strategic management by time. As the setting of corporate strategies takes a long and circular process, these three stages are overlapping with each other to a large degree. In addition, the activities at these three stages are of reciprocal causation relationship, because the guarantee mechanisms of strategy implementation, including corporate governance structure, organizational structure, management mechanism, leadership team formation and corporate culture, have also guaranteed the right strategic decision-making mechanism. In this sense, the division of three stages of corporate strategic management is just a logic-based division.

The irrationalism school's criticism on traditional strategic management thoughts and the "static paradigm" has been echoed by Chinese scholars because of the intense conflicts between the rationalism-based theories and China's practices of corporate strategic management. Over the past 20 years, under the influence of globalization and economic transition, the business environment faced by Chinese enterprises has demonstrated a strong dynamic trend. For example, business environment has become increasingly complex and volatile, interaction among different enterprises has become increasingly fast and competitive advantages has become increasingly difficult to maintain (Porter, 1980). More top managers have realized that, in a relatively dynamic competition environment, rapid response and innovation have become more important sources of competitive advantages and profit. Therefore, quite a number of the strategic decisions are made in the process of strategy implementation. In fact, corporate strategy behavior also includes some non-planned acts, positive response and innovation. In a relatively dynamic environment, enterprises at the strategic formation stage should not attach too much attention to goals, particularly, the formation and implementation of those very specific and quantified goals. Rather, top managers shall highlight the establishment and maintenance of their enterprises' strategic intent, tenet and positioning. Similarly, enterprises at this stage shall not be overly concerned about "details and specific steps", but to concentrate on response and innovation during the implementation of predetermined strategies. They should not stress only the logic process and scientific methods of strategic decision-making, but the underlying reasons and irrational factors influencing an enterprise's strategic decision making, such as corporate governance, organizational structure and management mechanisms, control method, composition of top management team and corporate culture, etc (Steiner and Kunin, 1983). 


\section{The integration: The "dynamic paradigm"}

Because of the crisis of strategic management practices faced by western enterprises, the irrationalism school has excessively criticized the rationalism school and its "static paradigm". However, rather than totally deny the rationalism, irrationalism school attempts to supplement and improve rationalistic theories and methods and better the "static paradigm". In order to challenge the long-standing dominance of rationalism in the field of corporate strategic management, the irrationalism school does not attempt to integrate theories and methods of the two genres. However, this fact could not prevent some scholars from trying to integrate the two streams of theories.

After a careful review and analysis of the history of western corporate strategic ideology and practices, Henry Mintzberg, the famous corporate strategic management scholar, attempted to integrate the viewpoints of both rationalism and irrationalism school. He firstly pointed out that strategy is a plan, which in fact is recognition of the traditional rationalism and the "static paradigm". However, Mintzberg also pointed out some of the defects existing in the traditional rationalism and the "static paradigm". As a conclusion, Mintzberg pointed out that the irrationalism school supplements and improves people's understanding of corporate strategy in the following area: 1) reveals that under the circumstances of limited information and time, how the values of corporate top executives and the entire corporate culture affect an enterprise's strategic decisions (Mintzberg thought strategy is also a pattern of behaviors); 2) reveals the importance of perspective and positioning in a relatively dynamic environment (Mintzberg thought strategy can also be a perspective or position); 3) reveals that strategy should not only include the making of some major, long-term and overall decisions, but also tactics and plots related with competition and interaction (Mintzberg thought strategy is an artifice or plot). However, the efforts made by Mintzberg in integrating the rationalism and irrationalism school focused mostly on clarification of strategy concepts by adopting a compatible method. Thus his conclusion is, comparatively speaking, may of less practical significances (Zhang and Lan, 2004).

To better apply Mintzberg's theory to the practice of corporate strategic management and to overcome the gap between China's current corporate strategic management theory and practice, this article attempts to transform Mintzberg's integration efforts into a new model to guide corporate strategic management practice, hoping to replace extensively criticized yet widely applied "static paradigm" in China's corporate strategic management. We call this strategic management mode more adaptive to dynamic environment the "dynamic paradigm". To make the mode easier to understand and follow, the 
"dynamic paradigm" is also nicknamed as a "river bed paradigm" for some features of river bed can express the essences of "dynamic paradigm" in a vivid way: 1) Drops of water can congregate and eventually become a big river contains tremendous power, an analog of the huge power contained in corporate strategies; 2) Though "river bed" regulates the basic trend and flow of the river, it also leaves much space for water in the river, an analog of the relationship between point decision-making and process decision-making; 3) All rivers flow eastwards in flexible routes is very much the same way like enterprises do in implementing their strategies, as shown in Fig. 2.

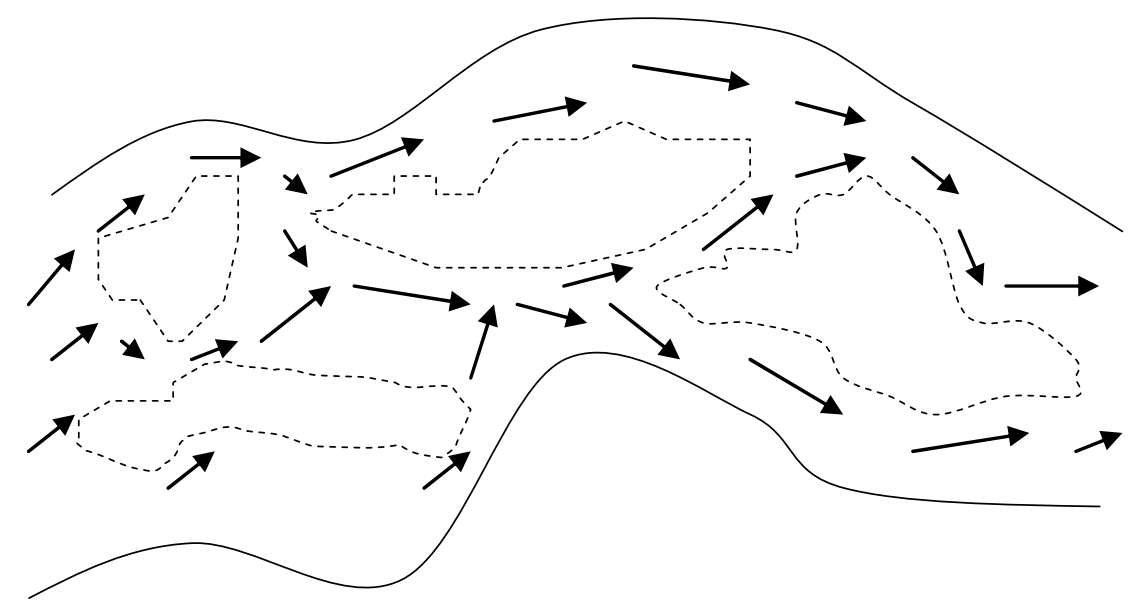

Fig. 2 Sketch map of the "dynamic paradigm" (the river bad paradigm) and "process decision-making" in corporate strategic management

The "dynamic paradigm" of corporate strategic management is established by absorbing the viewpoints of both rationalism and irrationalism school and improveing the traditional "static paradigm". In doing so, this paper tries to reveal the essential characteristics of corporate strategic management in a dynamic competitive environment, namely the nature of the "dynamic paradigm", in the following ways:

First, corporate strategic behaviors include both pre-planned acts and response acts. Strategic decision making is both a "point decision-making" and a "process decision-making". Decisions made at certain "points" are relatively macro-leveled, including intent, vision, purpose, position, methods, policies, principles, and means of implementation. Like river bed constrains the flow of a river, these preset frameworks can prevent an enterprise from losing its direction or control in making important strategic choices. At the same time, decision-making at the "point" shall not be too specific and quantitative. It must leave adequate contingency and innovative space to managers, allowing them to 
do some dynamic adjustments, try innovation and transformation to preset strategies in accordance with the external and internal environment changes and competitors' response during the process of strategy implementation. Effective strategies managers must be able to maintain a dynamic consistency between "preset plans" and "spontaneous response during the implementation of preset plans" and a dynamic continuity between the "point decision-making" and "process decision-making".

Second, effective formulation and implementation of strategy is affected by both rational and irrational factors. Recognition of this very fact helps top managers to make proper decision and choose suitable methods in accordance with different situations. For "point" decisions such as strategic intentions, objectives and positioning, more rational-oriented methods and analysis can be used. Whether these strategic intentions, objectives and positioning should be discarded or persisted during the latter implementation stage depend on an enterprise's concrete preference and choice. In implementing strategies, top managers shall learn to adapt to and cope with new situations and meet the requirement of speed and innovation. Under such circumstances, rational methods give way to irrational methods. Taking this into consideration, enterprises in a dynamic environment should attach great importance to corporate governance, organizational structure, management mechanisms, control mode, the top managers, the design and cultivation of corporate culture in order to improve the effectiveness and efficiency of their strategic management.

Third, since effective strategic managers must maintain dynamic consistency between "proactive plan" and "process reaction" and keep dynamic continuity between "point decision-making" and "process decision-making" by means of applying both rational and irrational methods. Thus the "dynamic paradigm" of strategic management no longer stresses the external differences and precedence relationship of the above three strategic management stages. Rather, it pays more attention to the inherent linkage and cross-impact among strategic management process among the three stages.

Acknowledgements I would like to express my gratitude to my $\mathrm{Ph}$. D student, Hu Zhanzhan in School of Business Administration of South China University of Technology for her work in translating this paper.

\section{References}

Abrahamson E, Fombrun C J (1994). Macrocultures: Determinants and consequences. Academy of Management Review, 19(4): 728-755

Andrews K R (1981). Replaying the board's role in formulating strategy. Harvard Business Review, 59(3): 18-27 
Ansoff H I (1965). Corporate Strategy. New York: McGraw-Hill

Chandler A D (1962). Strategy and Structure: Chapters in the History of the Industrial Enterprise. Cambridge, MA: MIT Press

Christensen C R, Andrews K R, Porter M E (1982). Business Policy: Text and Cases (fifth edition). Homewood, IL: Irwin

D’Aveni R A (1994). Hypercompetition: Managing the Dynamics of Strategic Maneuvering. New York: Free Press

George S D, David J R (1996). Wharton on Dynamic Competitive Strategy (first edition). New York: The Free Press

Hayes R H, Jaikumar R (1988). Manufacturing's crisis: New technologies, obsolete organizations. Harvard Business Review, 9: 77-85

Jelinek M, Amar D (1983). Implementing corporate strategy: Theory and reality. The Third Annual Conference of the Strategic Management Society, Paris

Lorange P (1980). Corporate Planning: An Executive Viewpoint. Englewood Cliffs, NJ: Prentice Hall

Mintzberg H, Ahlstrand B, Lampel J (1998). Strategy Safari. New York: Free Press

Mintzberg H (1994). The Rise and Fall of Strategic Planning. New York: Free Press

Mintzberg H (1987). Five Ps for Strategy. California Management Review, 30(1): 12-19

Porter M E (1980). Competivite Strategy: Techniques for Analyzing Industries and Competitors. New York: Free Press

Steiner G A (1969). Top Management Planning. New York: Macmillan

Steiner G A, Kunin H E (1983). Formal strategic planning in the United States today. Long Range Planning, 16(3): 12-17

蒋峦, 蓝海林 (Jiang Luan, Lan Hailin) (2004). 基于动态环境的企业竞争优势研究 (Research on Enterprises' Competitive Advantage under Dynamic Environment). 北京: 经济科学出版社 蓝海林 (Lan Hailin) (2004). 经济转型中国有企业集团行为的研究 (Research on Behaviors of China's State-owned Corporate Groups in Transitional Economy). 北京: 经济科学出版社

蓝海林 (Lan Hailin) (2001). 迈向世界级企业一一中国企业战略管理研究 (Become a World-leading Company-Research on China's Corporate Strategic Management). 北京: 企 业管理出版社

张平, 蓝海林 (Zhang Ping, Lan Hailin) (2004). 我国上市公司高层管理团队异质性与企业绩效 的关系研究 (Research on the Heterogeneity of the Upper Echelon of China's Listed Companies and Enterprise Performance). 北京: 经济科学出版社 